
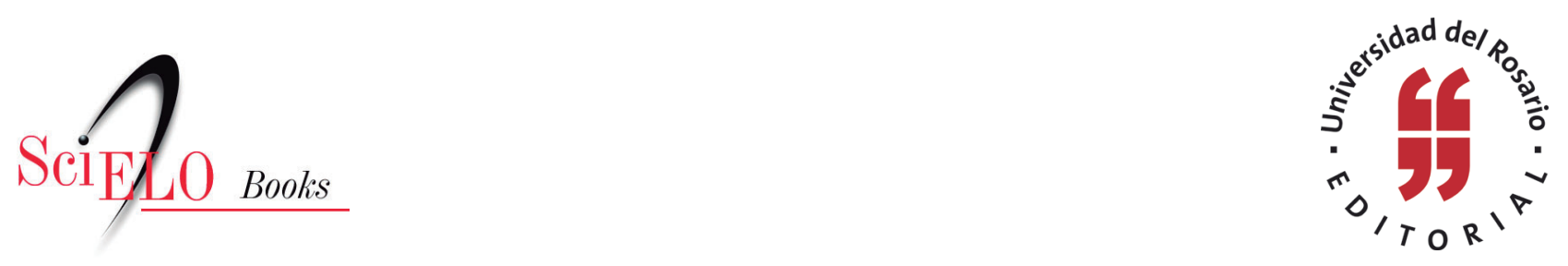

\title{
Desafíos conceptuales del bloque constitucional
}

\author{
María Alejandra Mercado Donato \\ Julieth Tatiana Rojas Pinzón
}

MERCADO DONATO, M.A., and ROJAS PINZÓN, J.T. Desafíos conceptuales del bloque constitucional. In: TORRES VILLARREAL, M.L., and IREGUI PARRA, P.M., ed. Discusiones contemporáneas sobre derechos humanos en el marco de la globalización [online]. Bogotá: Editorial Universidad del Rosario, 2015, pp. 63-87. ISBN: 978-958-738-671-4. https://doi.org/10.7476/9789587386714.0004.

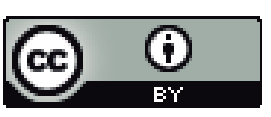

All the contents of this work, except where otherwise noted, is licensed under a Creative Commons Attribution 4.0 International license.

Todo o conteúdo deste trabalho, exceto quando houver ressalva, é publicado sob a licença Creative Commons Atribição $\underline{4.0}$.

Todo el contenido de esta obra, excepto donde se indique lo contrario, está bajo licencia de la licencia $\underline{\text { Creative }}$ Commons Reconocimento 4.0. 


\title{
Desafíos conceptuales del bloque constitucional
}

\author{
María Alejandra Mercado Donato* \\ Julieth Tatiana Rojas Pinzón**
}

\section{Resumen}

Uno de los problemas centrales del constitucionalismo contemporáneo es la convivencia entre normas de origen local y normas internacionales y la adecuada articulación de estas. La teoría constitucional ha intentado ofrecer herramientas teóricas para dar cuenta de este fenómeno. Una de ellas es la teoría del bloque constitucional, de acuerdo con la cual existen normas jurídicas que, aun cuando no se pueden asociar a ninguna cláusula de la Constitución formal, son relevantes al momento de decidir las cuestiones constitucionales. Sin embargo, no está claro cuál es el problema que en concreto se

* Estudiante de III semestre de Derecho en la Universidad de La Sabana, Cundinamarca, Colombia. Miembro del Semillero de Investigación "Fundamentos Filosóficos del Derecho Constitucional”. Correo electrónico: mariamedo@ unisabana.edu.co.

** Estudiante de III semestre de Derecho en la Universidad de La Sabana, Cundinamarca, Colombia. Miembro del Semillero de Investigación "Fundamentos Filosóficos del Derecho Constitucional”. Correo electrónico: juliethropi@ unisabana.edu.co. 
pretende abordar con la teoría del bloque constitucional. En este escrito sostenemos que la noción de bloque constitucional apunta a tres cuestiones distintas: 1) la determinación de fuentes o documentos jurídicos relevantes, 2) la definición de criterios de pertenencia de tales fuentes al ordenamiento jurídico-constitucional y 3) la definición de cuáles de esos documentos jurídicos resultan aplicables para resolver los casos constitucionales.

\section{Introducción}

\section{Un caso hipotético}

El Gobierno Nacional y un grupo guerrillero firmaron un acuerdo de paz, luego de décadas de conflicto armado en el país. En los meses siguientes a la firma del acuerdo, unos excombatientes guerrilleros fueron acusados de violación de derechos humanos por hechos ocurridos durante el periodo de preacuerdo de paz. Estas personas se entregaron a la justicia en el momento en que se firmó el acuerdo y fueron acusadas por la Fiscalía por genocidio y tortura.

De acuerdo con un tratado sobre derechos humanos, firmado y ratificado por Colombia, está prohibida la amnistía en caso de graves violaciones contra los derechos humanos y el derecho internacional humanitario, y en especial se exige que las víctimas y sus familiares puedan tener justicia por las violaciones cometidas (Tratado P). En otro tratado, por su parte, se establece que los Estados tienen derecho a la autodeterminación y en particular a definir la forma como resuelven sus problemas políticos (Tratado $\mathrm{P}$ ). Un tribunal internacional con jurisdicción sobre el Estado colombiano, al pronunciarse sobre un acuerdo similar en otro país del continente, aceptó la amnistía a favor de un grupo guerrillero con el propósito 
de que el país pudiera entrar en una nueva etapa de paz y tranquilidad en su sociedad (Decisión R). Por último, una ley estatutaria expedida por el Congreso de la República establece penas sustitutas para los miembros de los grupos guerrilleros que reconocieron crímenes.

En este contexto, un tribunal, conformado por los jueces Justino, Ulpiano y Pompeyo debía decidir sobre la imposición de una pena privativa de prisión a los integrantes del grupo guerrillero. El juez Justino, considerando que todos aquellos acuerdos internacionales que versen sobre derechos humanos, referidos por las cláusulas de reenvío, hacen parte del bloque constitucional (BC), vota por que se condene a los procesados. Sostiene que el Tratado $\mathrm{P}$ es vinculante en tanto hace parte del вс y además afirma que ni la jurisprudencia, ni la ley estatutaria son vinculantes, pues no hacen parte de la Constitución colombiana.

El juez Ulpiano, tomando la postura de que el вc lato sensu consiste en aquellas normas que no tienen rango constitucional, pero configuran parámetros para analizar la validez de las normas jurídicas, considera que debe absolverse a los condenados, puesto que el acuerdo busca, a través de lo pactado por la partes, conseguir la paz en la sociedad. Agrega que el Tratado $\mathrm{P}$, de acuerdo con jurisprudencia de la Corte Interamericana de Derechos Humanos, resulta aplicable solo para aquellos casos de autoamnistías en situaciones de transición de regímenes dictatoriales a democráticos. Considera asimismo que en el caso de los integrantes del grupo guerrillero, debe aplicarse la jurisprudencia del tribunal de $\mathrm{P}$, que acepta la amnistía a un grupo guerrillero a favor de la consecución de la tan anhelada paz nacional. Además, afirma que la ley estatutaria hace parte del вс y se constituye en referente normativo obligatorio para esta decisión. 
El último juez, Pompeyo, niega que el Tratado $\mathrm{P}$ tenga jerarquía constitucional, piensa que la Constitución está conformada exclusivamente por el documento de 1991 y sus reformas y que los tratados aludidos son criterios auxiliares de interpretación, y que por tanto su aplicación no es obligatoria. Concluye que se debe condenar a los acusados por no respetar el derecho a la vida consagrado en el artículo $11^{\circ}$ de la Constitución Política y que la exigencia de justicia en estos casos es un derecho inherente a la persona humana en los términos del artículo $94^{\circ}$ de la Constitución.

\section{Planteamiento del problema}

Uno de los problemas centrales del constitucionalismo contemporáneo es la convivencia entre normas de origen local y normas internacionales y su adecuada articulación. En el caso hipotético planteado se evidencia que la forma como se comprendan estas relaciones afecta la toma de decisiones, haciendo que un mismo juez pueda fallar de formas diversas frente al mismo caso concreto.

Desde décadas atrás se viene reconociendo que el concepto moderno de Constitución no es suficiente para dar cuenta de estas relaciones. Por ello la teoría constitucional ha intentado ofrecer herramientas teóricas que sirvan para responder a estos cambios. Una de ellas es la teoría del BC, de acuerdo con la cual existen normas jurídicas que, aun cuando no se pueden asociar a ninguna cláusula de la Constitución formal, son relevantes al momento de decidir las cuestiones constitucionales.

La Corte Constitucional ha empleado la teoría del вс para resolver diferentes cuestiones. Sin embargo, a pesar de algunos intentos de sistematización y precisión conceptual, el panorama sigue siendo confuso: ¿qué quiere decir que $\mathrm{X}$ pertenezca a BC? 
¿Significa que X hace parte de la Constitución? ¿Significa que es aplicable en casos constitucionales? ¿Cuáles son los criterios para determinar si $\mathrm{X}$ es вс? ¿Cómo puede ser que existan normas que no tengan jerarquía constitucional pero que sí determinen la validez constitucional de otras normas? ¿Cuál es la relevancia de distinguir entre вс lato sensu у вс stricto sensu? ¿A partir de qué criterios se hace esta diferenciación? Estos, entre otros problemas, solo pueden resolverse una vez se defina conceptualmente la noción de BC y su función normativa.

De acuerdo con esto el problema de investigación que abordamos en este trabajo puede formularse mediante la siguiente pregunta: ¿Cuál es el lugar del BC en el concepto de Constitución y cuáles son sus relaciones con el resto del ordenamiento jurídico? En otros términos, lo que se pretende determinar son las propiedades conceptuales de la noción de BC y de esta manera diferenciarlo de fenómenos similares. Entendemos que, como se planteó en el caso hipotético, determinar tales propiedades es una tarea esencial para una adecuada comprensión e implementación de las relaciones entre el derecho internacional y el derecho constitucional.

De acuerdo con lo anterior, en este trabajo se propone 1) señalar las deficiencias en la conceptualización de la noción de $\mathrm{BC}$ en la jurisprudencia de la Corte Constitucional y 2) delimitar la función del bloque constitucional en relación con la identificación de normas jurídicas, su pertenencia y aplicabilidad.

\section{Diseño metodológico}

Mediante una metodología analítico-sintética, en primer lugar se analiza la jurisprudencia de la Corte Constitucional en materia de bloque constitucional, con el objeto de identificar los elementos centrales de dicho bloque y la forma como ha sido 
empleado por esta corporación. Para el análisis del concepto de BC se partió del trabajo de sistematización de Uprimny (2005) y se estudiaron las sentencias de la Corte Constitucional que, posteriormente a dicho trabajo, emplearan explícitamente las nociones de $\mathrm{BC}$ en sentido lato y en sentido estricto. Luego, para dar cuenta del carácter sintético de la investigación, se reconstruyeron los elementos analizados en función de las nociones de pertenencia y aplicabilidad de las normas jurídicas planteadas por Raz (1991), Bulygin (1991), Rodríguez y Vicente (2009) y Navarro y Rodríguez (2014).

El objetivo general de la investigación consiste en comprender el concepto de BC en función de las nociones de pertenencia y aplicabilidad de las normas jurídicas, con el propósito de dar precisión conceptual al empleo de esta noción en la jurisprudencia constitucional. Para ello se plantearon los siguientes objetivos específicos: 1) examinar la jurisprudencia de la Corte Constitucional en aquellas decisiones en las que emplee expresamente las nociones de $\mathrm{BC}$ en sentido estricto y en sentido lato; 2) analizar el concepto de Constitución para definir el lugar de la noción de $\mathrm{BC} ; \mathrm{y} 3$ ) reconstruir las nociones de $\mathrm{BC}$ en sentido estricto y en sentido lato, de acuerdo con los elementos jurisprudenciales identificados y las nociones de pertenencia y aplicabilidad.

Este trabajo constituye un avance de esta investigación. En la primera parte de los resultados mostramos las tesis principales que identificamos en la jurisprudencia constitucional. En la segunda parte, en correspondencia con el segundo objetivo, ubicamos el concepto de $\mathrm{BC}$ y presentamos la importancia de plantear un marco teórico en función de los conceptos de pertenencia y aplicabilidad que permita superar las perplejidades en la comprensión y aplicación del вС. 


\section{La noción de bloque constitucional en la jurisprudencia de la Corte Constitucional}

El desarrollo jurisprudencial colombiano en materia de BC, como bien lo señala Uprimny (2005), ha sido lento y complejo; ha sufrido varios cambios a través del tiempo, especialmente después de la Constitución de 1991, puesto que en ella se establece el reconocimiento de los tratados internacionales en materia de derechos humanos (cláusulas de reenvío). ${ }^{1}$

La primera etapa es la comprendida entre 1992 y 1994, en la cual se dan los primeros e incipientes acercamientos al BC por parte de la Corte Constitucional, dejando como resultado el reconocimiento del Pacto de Derechos Económicos, Sociales y Culturales como parte del ordenamiento jurídico colombiano, y reconociéndolo como aplicable (Sentencia T-426 de 1992). Debido a ello es posible deducir que el concepto presente durante aquel periodo era el de $\mathrm{BC}$ entendido como tratados firmados y ratificados por Colombia, y usados como método interpretativo aplicable dentro de la jurisprudencia nacional (Uprimny, 2005).

En la segunda etapa (1995 a 1996) se incorpora por primera vez el término "bloque constitucional", creado inicialmente por el Consejo Constitucional francés, en la Sentencia C-225 de1995, y que se define como las normas de carácter humanitario que no pueden dejar de aplicarse en estados de excepción, gracias a la existencia del artículo 93 de la Carta Política (Uprimny, 2005).

1 Gutiérrez Beltrán (2007) hace un estudio más general del bloque constitucional en Colombia. Sin embargo, hemos decidido enfatizar en el estudio de Uprimny dado que incluye un enfoque iusteórico explícito en relación con la diferencia entre jerarquía constitucional y aplicabilidad constitucional, que resulta más adecuado para los efectos de este trabajo. Pueden verse también los trabajos de Olano (2005) y Rey Cantor (2006). 
Finalmente, desde 1997 se hacen las primeras aproximaciones a una sistematización doctrinal para precisar los alcances y metodologías que debían implementarse en los casos en que se usara el вc. Del mismo modo, se lleva a cabo una delimitación enfocada a determinar las disposiciones que harían parte de este, así como una expansión normativa con respecto a la recepción de nuevos materiales jurídicos internacionales que recen sobre derechos humanos, como el convenio con la Organización Internacional del Trabajo (OIT) y la jurisprudencia foránea (Uprimny, 2005).

Dados los diferentes matices de la noción de Bc, la jurisprudencia constitucional ha distinguido entre $\mathrm{BC}$ stricto sensu у вс lato sensu. El primero incluye al preámbulo, los tratados internacionales firmados y ratificados por Colombia en materia de límites territoriales, derecho humanitario y derechos intangibles, derechos reconocidos por la Carta política que también sean reconocidos en dichos acuerdos, y el articulado constitucional. El segundo agrega a los elementos anteriormente mencionados, las leyes estatutarias y orgánicas nacionales. ${ }^{2}$

En todo caso, y para lo que en concreto importa a este trabajo, de acuerdo con la sistematización de Uprimny, en la conceptualización del вс se debe diferenciar entre 1) las normas de rango constitucional, 2) los parámetros de constitucionalidad de las leyes y 3) las normas que son constitucionalmente relevantes en un caso específico; es decir, de acuerdo con este autor, la noción de вс es ambigua y se refiere a objetos distintos aun cuando relacionados. Primero se refiere a las normas

2 El concepto de bloque constitucional, como se verá más adelante, no ha sido nada pacífico en la jurisprudencia constitucional, puesto que ha tenido distintas conceptualizaciones a través del tiempo. 
que hacen parte de la Constitución, segundo a normas que funcionan como parámetros para efectuar el juicio de constitucionalidad de las leyes, y tercero a normas que — sin ser parte de la Constitución ni funcionar como parámetro en los juicios de constitucionalidad - resultan relevantes para resolver los casos concretos. Uprimny concluye que la naturaleza de la noción no es nítida, el mecanismo de incorporación de las normas al вс no es claro, ni tampoco lo son las normas y principios que lo integran.

A pesar de las conclusiones y recomendaciones de Uprimny, la jurisprudencia posterior de la Corte Constitucional no ha sido clara en el empleo de la noción de BC. Así, en la Sentencia C-047 de 2006, en la cual se debía determinar si la posibilidad de apelar una sentencia absolutoria en materia penal violaba el principio del non bis in idem, se explicó que la apelación era parte del mismo proceso, puesto que es una segunda instancia y no hay tratados internacionales de derechos humanos que la prohíban. Se agregó que el derecho a impugnar una sentencia condenatoria y la garantía de non bis in idem no están previstos de manera expresa entre aquellos derechos que no son susceptibles de ser suspendidos durante un estado de excepción, esto de acuerdo con el Pacto Internacional de Derechos Civiles y Políticos y la Convención Americana de Derechos Humanos.

Con base en las anteriores consideraciones, la Corte declaró exequibles los apartes citados, pues dicha apelación — considera la Corporación - no vulnera el principio en mención. En esta sentencia se sostuvo que la Convención es un criterio obligatorio para la constitucionalidad (validez) de las normas jurídicas. Para explicar en qué sentido tales normas (como la Convención) se constituyen en criterios obligatorios de constitucionalidad, la Corte recurrió a la noción de вс, recordando la distinción entre вС stricto sensu y lato sensu. Por stricto sensu 
entendió aquellas normas que tienen jerarquía constitucional, y por lato sensu aquellas normas que si bien carecen de rango constitucional, configuran parámetros para analizar la validez de las normas jurídicas. En este mismo sentido agregó:

Así, de acuerdo con la jurisprudencia constitucional, integran el bloque de constitucionalidad en sentido lato: (i) el preámbulo, (ii) el articulado de la Constitución,(iii) algunos tratados y convenios internacionales de derechos humanos (C.P. art.93), (iv) las leyes orgánicas y, (v) en algunas ocasiones, las leyes estatutarias. (Sentencia C-047 del 2006, p. 21)

La Corte sostiene que el вс en sentido lato, el cual configura parámetros de análisis de validez de las normas, y que se supone no tiene rango constitucional, está integrado por el contenido formal de la Constitución, es decir, el preámbulo y el articulado (que son disposiciones y se suponen Constitución en sentido formal); además lo integran tratados que versen sobre derechos humanos, las leyes orgánicas y las estatutarias. De lo dispuesto se desprenden dos problemas evidentes: el primero es el planteamiento de si las disposiciones constitucionales son $\mathrm{BC}$, lo que representaría una contradicción evidente de la Corte, ya que la diferenciación entre Constitución en sentido material y Constitución en sentido formal dejaría de existir, para transformarse todo en material constitucional. El segundo es que al clasificar los tratados y convenios internacionales en el вс lato sensu, estos dejarían de tener rango constitucional y pasarían a ser meros parámetros de configuración del análisis de la validez de normas jurídicas internas.

Dos años después, en la Sentencia C-617 del 2008, la Corte resolvió una demanda de constitucionalidad de los artículos $362^{\circ}$ (parcial) y $432^{\circ}$, numeral $2^{\circ}$, del Código Sustantivo del 
Trabajo, en los cuales se definen los requisitos mínimos que necesita una agremiación sindical para ser reconocida como tal, así como las condiciones formales que deben cumplir las personas que, llegado el caso, representen a dicha agremiación frente a conflictos colectivos. Los demandantes consideraron que con ello se violaban el preámbulo y el artículo $2^{\circ}$ de la Constitución, así como el numeral $2^{\circ}$ del artículo $3^{\circ}$ del Convenio 87 de la оiт. Por lo tanto, fue competencia de la Corte "determinar inicialmente si el referido convenio sirve como parámetro para apreciar la constitucionalidad de la disposición examinada"(Sentencia C-617 del 2008, p. 14).

Para aclarar la aplicabilidad del Convenio 87 de la oit en el caso expuesto por las demandantes, la Corte definió el concepto de вС e hizo distinción entre lato sensu y stricto sensu. En este sentido sostuvo:

[...] el mencionado bloque reúne un conjunto de normas y principios que, aún cuando no aparecen formalmente en el texto constitucional, se entienden integrados a la Constitución y hacen parte de ella. Junto a esta noción estricta, la jurisprudencia constitucional ha forjado una noción amplia, según la cual el bloque "estaría compuesto por todas aquellas normas de diversa jerarquía, que sirven de parámetro para llevar a cabo el control de constitucionalidad de la legislación”. (Sentencia C-617 del 2008, p. 14)

Hasta ese punto la Corte, al parecer, mantenía los conceptos que había planteado en sentencias anteriores, especialmente en la Sentencia C-047 del 2006, en donde definió вс stricto sensu como todas las normas aplicables al ordenamiento jurídico colombiano y que no hacían parte de la Constitución en sentido formal, pero tenían rango constitucional, y lato 
sensu como todas las normas que servían como criterio interpretativo, aun cuando no tuvieran rango constitucional, como es el caso de las normas estatutarias.

A este concepto ya bien conocido de BC la Corte (2008) agregó en la misma sentencia lo siguiente:

[...] la determinación de los elementos que conforman el bloque de constitucionalidad, ya sea en el sentido amplio o en su sentido estricto, así como la definición del rango de cada uno corresponde a la Corte Constitucional y, en consecuencia, su inclusión y el alcance de esa inclusión dependen del examen adelantado por la Corporación en cada caso, así como de las materias previstas en las disposiciones o en el respectivo tratado o convenio. (Sentencia C-617 del 2008, p. 15)

La Corte incluyó un nuevo presupuesto al concepto de BC, y es que es ella misma la competente para definir, en cada caso, cuáles materiales hacen parte del BC y cuáles no, así como el sentido en el que pertenecen (lato o stricto sensu), lo que tiene un claro impacto en el rango que van a tener dichas disposiciones.

Posteriormente, en la Sentencia C-228 del 2009, la Corte se volvió a pronunciar sobre el $\mathrm{BC}$, a la luz de una demanda al artículo $3^{\circ}$ de la Ley 1101 del 2006, mejor conocida como Ley General de Turismo, donde se determinan los aportes de la contribución parafiscal para la promoción del turismo, por considerar que se viola el artículo $29^{\circ}$ del Estatuto Orgánico del Presupuesto (Decreto 111 de 1996), que a su vez corresponde al artículo $2^{\circ}$ de la Ley 225 de 1995, además de vulnerarse los artículos 95, 363 y 150 de la Carta Política. La Corte analizó el concepto de $\mathrm{BC}$ para determinar si dicho 
estatuto hacía parte de él y aplicarlo al caso concreto de esta demanda. Así, definió que

[...] forman parte del bloque de constitucionalidad aquellas reglas y principios que, sin figurar expresamente en la Carta, tienen rango constitucional (bloque de constitucionalidad en sentido estricto) o al menos representan parámetros de constitucionalidad (bloque de constitucionalidad en sentido lato) que permiten controlar la constitucionalidad de las leyes y de las normas de inferior jerarquía, por cuanto la propia Constitución, por medio de cláusulas de remisión, confiere fuerza jurídica especial a esas reglas y principios. (Sentencia C-228 del 2009, p. 28)

Fue así como la Corte trató de mantener su precedente con respecto al вс, especialmente el de la Sentencia C-047 del 2006, donde el sentido lato es un criterio interpretativo, sin rango constitucional, y el sentido estricto son disposiciones jurídicas distintas a la Constitución que gozan del mismo rango dentro del ordenamiento jurídico nacional. Ambos son parámetros de legitimidad constitucional, aunque no tienen el mismo rango dentro de la pirámide normativa. Por lo tanto, "todas las normas que integran el bloque de constitucionalidad son parámetros necesarios e indispensables para el proceso de creación de la ley" (p. 28) y se facilita el control de constitucionalidad. Asimismo, la Corte trajo a colación la importancia de la existencia de cláusulas de remisión para el concepto de $\mathrm{BC}$, como leyes legitimadoras e integradoras de tratados internacionales que versen únicamente sobre temas de derechos humanos.

La sentencia no solo recoge aspectos mencionados en la jurisprudencia anterior, además menciona que las leyes 
estatutarias hacen parte del $\mathrm{BC}$, tienen rango constitucional y se usan como método de acercar la Constitución a las leyes ordinarias y poder hacer un mejor control de constitucionalidad de ellas.

Como la Corte misma ha reconocido, "entender que el respeto de las normas de rango legal para el ejercicio de dicho control, es un tópico que a primera vista parecería contradictorio" (Sentencia C-047 del 2006, p. 29), puesto que el objeto mismo del control constitucional, y el uso del вс en este, es el de hacer un juicio de adecuación entre la Constitución y las demás leyes. Sin embargo, para la Corte es claro que lograr hacer dichos juicios en algunos casos concretos no es tarea fácil, especialmente cuando las disposiciones constitucionales son demasiado amplias y lejanas del contexto de aplicación de las leyes, y es en este marco en que la Corte considera que una ley estatutaria puede ser entendida como parte del BC, pues funciona como puente de comunicación entre la Constitución y la ley ordinaria:

Estas leyes que permiten determinar el alcance pleno de las normas constitucionales y de esta forma apreciar en un caso concreto la constitucionalidad de otra ley enjuiciada cumplen funciones de parámetro complementario o de norma interpuesta. (Sentencia C-047 del 2006, p. 30)

Adicionalmente, la ley estatutaria cumple con presupuestos constitucionales de carácter formal, los cuales hacen que exista una relación diferente entre leyes ordinarias entre sí y con leyes estatutarias, puesto que las primeras no pueden derogar en ningún caso las segundas, mientras que el proceso contrario puede suceder sin inconvenientes. Asimismo, las leyes estatutarias tienen un proceso de expedición diferente 
al de las leyes ordinarias. Todo lo anterior deriva en que, en algunos casos, "[...] La norma objeto de control (B) se compara con la norma constitucional (A), y a su vez esta última adquiere su verdadero alcance a partir de la consideración de la norma legal orgánica o estatutaria (C)" (Sentencia C-047 del 2006, p. 30).

La Corte hace una nueva interpretación del Bc, que complementa el concepto que se había desarrollado, especialmente en lo referente al lato sensu, incluyendo las leyes estatutarias como parte del bloque en este sentido. Como la Corte misma dijo:

[...] las referidas leyes orgánica y estatutaria pueden ser utilizadas como parámetro de control de constitucionalidad, en tanto (i) determinan en algunos casos el alcance real de las normas constitucionales y (ii) su contenido, según la Constitución, enmarca los límites a los que deben ceñirse otras leyes, lo cual configura la exigencia de un trámite especial en ciertos temas (trámite de ley orgánica o estatutaria), que debe ser respetado so pena de vulnerar los principios constitucionales que la contienen. (Sentencia C-047 del 2006, p. 30)

El análisis de las sentencias deja claro la existencia de ambigüedad en la noción de вс con respecto a la identificación y aplicación del derecho. Asimismo, se plantea que la Convención Interamericana representa un criterio obligatorio para la constitucionalidad de las normas, mientras que en lo referente al BC en stricto sensu, parece haber precisión en que consiste en normas de jerarquía constitucional, lo que quiere decir que es un conjunto de normas que, si bien no aparecen en el texto, se entienden integradas a la Constitución y hacen parte de ella. 
Del вс en amplio lato se dice que lo conforman todas aquellas normas de diversa jerarquía que sirven de parámetro para el control constitucional, lo cual indica que no tendrían rango de constitucionalidad, al menos, no todas ellas. La misma Corte, en las sentencias del 2009, afirma que la determinación de los elementos que forman parte del $\mathrm{BC}$ depende del análisis que haga ella después en cada caso, y esto último podría acarrear inseguridad jurídica, al desconocerse qué debe ser acatado o no por los jueces en lo referente al вc lato sensu.

Del análisis de la Corte en la primera sentencia objeto de estudio, donde se hace mención de la Constitución en sentido formal como parte del вс en amplio sentido, о lato sensu, se infiere que la Corte da a entender por ello todo el material constitucional que no sea tratado internacional de derechos humanos. En este orden de ideas, si el BC es Constitución en sentido material, que se diferencia del formal por no estar contenido en los textos constitucionales, si el texto se entendiera como material constitucional, no habría necesidad de hacer la diferenciación y toda la Constitución (texto y demás material) sería material jurídico relevante.

De las sentencias también se desprende que el BC en sentido lato consiste en aquellas normas que aun cuando no tienen rango constitucional, configuran parámetros para analizar la validez de las normas jurídicas. Entonces, ¿`a qué hacen referencia estos parámetros?, ¿qué significan? Si son configurados para analizar la validez de las normas jurídicas, podrán consistir en reglas para determinar el alcance de las normas constitucionales, lo que quiere decir que conforman criterios de interpretación, que marcan límites a los límites a los que deben ceñirse estas normas.

En definitiva, de acuerdo con lo dicho se pueden identificar las siguientes tesis sobre la noción de BC: 
- Tesis 1: en la conceptualización del вс se debe diferenciar entre 1) las normas de rango constitucional, 2) los parámetros de constitucionalidad de las leyes y 3) las normas que son constitucionalmente relevantes en un caso específico (Uprimny).

- Tesis 2: el вс está conformado por el conjunto de normas que constituyen un criterio obligatorio para la validez de las normas jurídicas (Sentencia C-047 del 2006).

- Tesis 3: se entiende por BC stricto sensu aquellas normas que tienen rango constitucional, y por lato sensu aquellas normas que no tienen rango constitucional, pero sirven como criterio de validez de las normas jurídicos (sentencias C-047 del 2006, C-617 del 2008 y C-228 del 2009).

- Tesis 4: la Corte Constitucional es la que determina los elementos que comprenden el Bc, tanto en stricto como en lato sensu, y el alcance de cada elemento será determinado por ella en cada caso del que deba conocer (Sentencia C-617 del 2008).

\section{Constitución en sentido material: ¿¿cuál es el lugar del bloque constitucional?}

Las dinámicas de la globalización suponen retos a la comprensión tradicional de la Constitución y sus relaciones con el derecho internacional. No solo la Constitución funciona más allá de las fronteras nacionales, sino que el derecho internacional suele desarrollar funciones constitucionales. Estas características han llevado a algunos autores a formular la existencia de un derecho constitucional transnacional, caracterizado por el desarrollo de arreglos constitucionales transnacionales, el empleo de decisiones judiciales en diferentes contextos (v.gr., 
diálogos y precedentes internacionales) y la definición de normas y parámetros internacionales comunes a constituciones de diferentes Estados (Yhe y Chang, 2008).

De acuerdo con esto, una de las características principales de la teoría constitucional contemporánea es que debe dar cuenta de las dinámicas transnacionales de las fuentes jurídicas, y dentro de esto explicar la cuestión acerca de la identificación de la Constitución. Para esta tarea se deben investigar los criterios que permitan establecer el papel de las normas jurídicas en un contexto en el que las fuentes nacionales son insuficientes. ${ }^{3}$

En el marco de esta problemática, la dogmática constitucional ha desarrollado la distinción entre Constitución en sentido formal y Constitución en sentido material. ${ }^{4}$ La primera es el documento promulgado por el acto constituyente o sus reformas; en otras palabras, es el documento escrito aprobado mediante un acto constituyente (primario o secundario). Por ello, en aquellos Estados que cuentan con una Constitución escrita no debería existir mayor dificultad para identificar la Constitución en sentido formal. En contraste, la identificación de la Constitución en sentido material no es una tarea igual de sencilla. La dificultad obedece a que la Constitución material apunta a dos cuestiones distintas: la primera referida

3 Sobre la noción de bloque constitucional y la importancia de las relaciones con los ordenamientos jurídicos nacionales, véase Ramelli (2004), quien aborda el tema desde un enfoque internacionalista.

4 Con respecto a la relación entre Constitución en sentido material y bloque constitucional, véase Bidart (1995) y Rey Cantor (2006). En todo caso, debe tenerse en cuenta que esta distinción fue plantada por Kelsen (1958) y ha sido empleada en distintos contextos para justificar la existencia de normas constitucionales más allá de los documentos constitucionales. Véase, por ejemplo, la noción de Constitución sedimentaria en Friedman y Smith (1998), o la de la distinción entre Constitución histórica y práctica constitucional en Nino (1992). 
a la identificación de los documentos jurídicos relevantes y la segunda a la determinación de las normas jurídicas.

La noción de Constitución en sentido material se refiere, de una parte, al conjunto de documentos (y no solamente la Constitución formal) que conforman la Constitución, y, de otra parte, al conjunto de normas que hacen parte de la Constitución. Esta diferencia se entiende mediante la conocida distinción entre disposiciones normativas y normas. Las primeras son actos lingüísticos de las autoridades jurídicas que crean o reconocen normas jurídicas, en tanto que las segundas suelen entenderse como el enunciado normativo y su significado. Las normas son el significado de las disposiciones que se refieren al otorgamiento de poderes o a la definición de un caso como jurídicamente prohibido, obligatorio o facultativo. De acuerdo con esto, la Constitución en sentido material puede referirse, por una parte, al conjunto de disposiciones constitucionales, y por la otra, al conjunto de normas jurídicas constitucionales. $^{5}$

Teniendo en cuenta lo anterior, la cuestión acerca de cuál es el lugar de la noción de BC en el concepto de Constitución debe apuntar, en un primer momento, a la definición de si es un problema referido a la identificación de documentos o a la determinación de normas. De acuerdo con lo estudiado en el punto anterior, la cuestión del вс de la forma, como se ha planteado en la jurisprudencia constitucional, se refiere a la identificación de documentos jurídicos relevantes. En otras palabras, el problema del вс constitucional es una cuestión relativa a los criterios de identificación de documentos o materiales jurídicos

5 Esta distinción puede verse en Atienza y Manero (1996, pp. 46-76), Rodríguez (2002), Alchourron y Bulygin (1974) y Bulygin (2004). 
relevantes, y no una tarea de interpretar o identificar las normas jurídicas relevantes para resolver un caso.

Por otra parte, la teoría jurídica diferencia entre pertenencia de la norma a un ordenamiento jurídico y aplicabilidad de esta. Así, una norma jurídica pertenece a un ordenamiento jurídico cuando, de acuerdo con los criterios de identificación existentes, se puede afirmar que hace parte de él. Por otra parte, una norma es aplicable cuando el derecho exige que los órganos decisores le otorguen autoridad con respecto a un caso. En función de las relaciones entre pertenencia y aplicabilidad, existe acuerdo en torno a que los ordenamientos constitucionales son sistemas abiertos, y por lo tanto otorgan valor normativo a disposiciones jurídicas de forma independiente a su pertenencia (Bulygin, 2001; Raz, 1991).

Como consecuencia de esta distinción, no existe una conexión necesaria entre aplicabilidad y pertenencia de una norma a un sistema jurídico; es decir, una norma puede pertenecer a un sistema jurídico y no ser aplicable (v.gr., una disposición jurídica inconstitucional que no ha sido declarada inexequible con efectos erga omnes). Asimismo, una norma puede ser aplicable sin pertenecer al ordenamiento jurídico (v. gr., una norma derogada con efectos ultractivos). En definitiva, la cuestión determinante es si las nociones de pertenencia y aplicabilidad son distintas y, por tanto, obedecen a criterios distintos. ${ }^{6}$

En suma, el problema del BC constitucional obedece a la cuestión de qué documentos jurídicos a) pertenecen al ordenamiento jurídico constitucional y b) qué documentos jurídicos resultan aplicables para resolver los casos constitucionales. De acuerdo con lo primero, la noción de $\mathrm{BC}$ debe ofrecer una

6 Este asunto ha sido analizado con respecto a las normas de derecho internacional por Rodríguez y Vicente (2011). 
respuesta a la determinación de los criterios para identificar los materiales jurídicos (las disposiciones jurídicas) que pertenecen a la Constitución. De acuerdo con lo segundo, dicha noción debe ofrecer una explicación de los criterios que hacen que documentos externos al ordenamiento constitucional sean aplicables.

En términos de Hart (1963, 1994), el problema de la pertenencia depende de la noción de regla de reconocimiento, la cual establece los criterios últimos de identificación de normas pertenecientes a un sistema jurídico determinado. Lo que identifica a un sistema jurídico — siguiendo con Hart - es que este, además de establecer las acciones que los agentes deben o no realizar (reglas primarias), contiene normas necesarias para definir, aplicar y modificar tales deberes (reglas secundarias).

Para la existencia del ordenamiento jurídico resulta determinante la noción de aceptación de la regla de reconocimiento, por ejemplo, la práctica de usar de manera compartida los criterios de validez jurídica incorporados a la regla de reconocimiento, y criticar a quienes se aparten de ella. Sin embargo, como se dijo, no existe una conexión necesaria entre pertenencia y aplicabilidad. Existen normas que aun cuando no pertenecen al ordenamiento jurídico, no pueden ser ignoradas por los jueces al momento de justificar las decisiones. La característica central que tiene como consecuencia la distinción entre pertenencia y aplicabilidad, es que los ordenamientos jurídicos son necesariamente abiertos, es decir, tienen una naturaleza abierta a consideraciones normativas extrasistemáticas (Raz, 1991; Navarro y Rodríguez, 2014).

De acuerdo con lo anterior, no parecen existir dudas en torno a que una adecuada explicación de la noción de $\mathrm{BC}$ depende de la forma como se definan los criterios de pertenencia 
y de aplicabilidad, así como de la forma en que se conceptualicen las diferencias entre tales conceptos. La perplejidad que generan las inconsistencias entre las tesis identificadas en el punto anterior de este trabajo, es una buena muestra de la necesidad de hacer estas precisiones conceptuales.

\section{Conclusiones}

De acuerdo con el análisis de la jurisprudencia de la Corte Constitucional, se identificaron las siguientes tesis: 1) el вс está conformado por el conjunto de normas que constituyen un criterio obligatorio para la validez de las normas jurídicas; 2) el вс stricto sensu lo constituyen aquellas normas que tienen rango constitucional, en tanto que por вс lato sensu se entienden aquellas normas que no tienen rango constitucional, pero sirven como criterio de validez de las normas jurídicas; 3) la Corte Constitucional es la que determina los elementos que comprenden el вс, tanto stricto como lato sensu, y es ella la que determina el alcance de cada elemento en cada caso del que deba conocer.

Estas tesis no dan respuesta acerca de la naturaleza de la noción de вс ni tampoco con respecto a los criterios para definir cuándo una norma se constituye en criterio obligatorio de validez o en qué sentido se puede afirmar que una norma que no hace parte del ordenamiento constitucional pueda constituirse en criterio de validez de las normas jurídicas.

La propuesta de Uprimny de distinguir entre 1) normas de rango constitucional, 2) parámetros de constitucionalidad de las leyes y 3 ) normas que son constitucionalmente relevantes en un caso específico (Uprimny), no ha sido desarrollada y, en consecuencia, no ofrece un marco conceptual adecuado para comprender los problemas abordados con la noción de BC.

De acuerdo con los resultados que arroja el avance de nuestra investigación, una adecuada comprensión de estos 
aspectos lleva a afirmar que el problema del вс debe ser abordado desde distintos niveles de análisis. Por una parte, la cuestión del BC, como se ha planteado en la jurisprudencia constitucional, se refiere a la identificación de documentos jurídicos relevantes. En otras palabras, el problema del вс constitucional es una cuestión relativa a los criterios de identificación de documentos o materiales jurídicos relevantes y no una tarea de interpretar o identificar las normas jurídicas relevantes para resolver un caso. En síntesis:

1) El problema del $\mathrm{BC}$ constitucional obedece a la cuestión de qué documentos jurídicos a) pertenecen al ordenamiento jurídico constitucional y b) qué documentos jurídicos resultan aplicables para resolver los casos constitucionales.

2) De acuerdo con lo primero, la noción de Bc debe ofrecer una respuesta a la determinación de los criterios para identificar los materiales jurídicos (las disposiciones jurídicas) que pertenecen a la Constitución. De acuerdo con lo segundo, la noción de вс debe ofrecer una explicación de los criterios que hacen que documentos externos al ordenamiento constitucional sean aplicables.

3) Los asuntos relacionados con la pertenencia, aplicabilidad o el modelo de explicación de los preceptos obedecen a criterios y objetos de análisis distintos y, por tanto, a metodologías de estudio diferentes. En definitiva, la confusión entre niveles de análisis dificulta la adecuada comprensión de las relaciones entre el derecho constitucional y el derecho internacional $y$, en consecuencia, entorpece la posibilidad de una adecuada articulación entre ellos. 


\section{Referencias}

Alchourron, C. y Bulygin, E. (1974). Introducción a la metodología de las ciencias juridicas y sociales. Buenos Aires: Astrea.

Atienza, M.y Manero,J. (1996). Las piezas del derecho. Barcelona: Ariel.

Bidart, G. (1995). El derecho de la Constitución y su fuerza normativa. Buenos Aires: Sociedad Anónima Editora Comercial, Industrial y Financiera.

Bulygin, E. (1991). Algunas consideraciones sobre los sistemas jurídicos. Doxa: Cuadernos de Filosofía del Derecho, 9 (9), 257-279.

Bulygin, E. (2007). Creación y aplicación del derecho en Atria, Bullygin, Moreso, Navarro, Rodríguez y Ruiz Manero, lagunas en el derecho. Barcelona: Marcial Pons.

Colombia, Corte Constitucional (2008). Sentencia C-617.

Colombia, Corte Constitucional (2006). Sentencia C-047. M. P. Rodrigo Escobar Gil.

Colombia, Corte Constitucional (1995). Sentencia C-225. M. P. Alejandro Martínez Caballero.

Colombia, Corte Constitucional (2009). Sentencia C-228. M. P. Humberto Antonio Sierra Porto.

Friedman, B. y Smith, S. (1998). The Sedimentary Constitution. University of Pennsylvania Law Review, 147 (1), 1-90.

Gutiérrez Beltrán, A. (2007). El bloque de constitucionalidad, conceptos y fundamentos. Bogotá: Editorial Universidad Externado de Colombia.

Hart, H. (1963). The Concept of Law. Oxford.

Hart, H. (1994). The Concept of Law (2a ed.). Oxford.

Kelsen, H. (1995). Teoría general del derecho y del Estado. (Quinta reimpresión de la segunda edición). México D. F.: Universidad Nacional Autónoma de México. 
Navarro, P.y Rodríguez, J. (2014). Deontic Logic and Legal Systems. En Cambridge Introductions to Philosophy and Law. Cambridge.

Nino, C. S. (1992). Fundamentos de derecho constitucional. Buenos Aires: Astrea.

Olano, H. (2005). El bloque de constitucionalidad en Colombia. Estudios Constitucionales, 3 (1), 231-242.

Ramelli Arteaga, A. (2004). Sistema de fuentes de derecho internacional público y bloque de constitucionalidad en Colombia. Cuestiones Constitucionales: Revista Mexicana de Derecho Constitucional, (11).

Raz, J. (1990). Practical Reason and Norms. Oxford: Oxford University Press.

Rey Cantor, E. (2006). El bloque de constitucionalidad. Aplicación de tratados internacionales de derechos humanos. Estudios Constitucionales, 4 (2), 299-334.

Rodríguez J. L. y Vicente, D. E. (2009). Aplicabilidad y validez de las normas del derecho internacional. Doxa: Cuadernos de Filosofía del Derecho, (32). Recuperado el 27 de enero del 2015, de http://www.cervantesvirtual.com/obra/doxa-3/

Rodríguez,J.(2002). Lógica de los sistemas jurídicos. Madrid: Centro de Estudios Políticos Constitucionales.

Uprimny, R.(2005). El bloque de constitucionalidad en Colombia. Recuperado el 30 de enero del 2015, de http://redescuelascsa.com/sitio/repo/DJS-Bloque_Constitucionalidad\%28Uprimny\%29. pdf

Yeh,J. R.y Chang,W.C. (2008). The Emergence of Transnational Constitutionalism: Its Features, Challenges and Solutions. Penn State International Law Review, 27 (1). Recuperado el 27 de enero del 2015, de http://ssrn.com/abstract=1636163 
Este libro fue compuesto en caracteres Adobe Caslon Pro 11,2 puntos, impreso en propal de 70 gramos y encuadernado con método hot melt en octubre de 2015, en Bogotá, D. C., Colombia 